\title{
Assessment of Soluble Urokinase-Type Plasminogen Activator Receptor (suPAR) in Chronic Obstructive Pulmonary Disease

\section{Abstract}

Background: Chronic obstructive pulmonary disease (COPD) is a disease characterized by a progressive airflow limitation. Soluble urokinase-type plasminogen activator receptor (suPAR) is released from the membrane-bound plasminogen activator, and is positively correlated with the activation of immune system.

Aims: Release of inflammatory mediators is increased in chronic obstructive pulmonary disease (COPD), particularly during exacerbations. The objective of this study was to compare plasma levels of suPAR and serum levels of C-reactive protein (CRP) during exacerbation and stable periods in patients with COPD.

Study Design: Prospective clinical study.

Methods: The patients with COPD were divided into 3 groups for evaluations: those with stable COPD [SCOPD] $(n=54)$, pre-treatment acute exacerbation COPD [AECOPD] $(n=53)$, and post-treatment AECOPD $(n=52)$. Plasma suPARand serum CRP levels were assessed for each patient.

Results: Whereas the increased serum CRP levels of the participants were $54.82 \pm 56.63 \mathrm{mg} / \mathrm{l}$ during acute exacerbation period, during the stable period it was $5.02 \pm 6.31 \mathrm{mg} / \mathrm{l}$ and statistically significant $(p=$ $0.0001)$. The suPAR level was $1.28 \pm 0.52 \mathrm{ng} / \mathrm{ml}$ during the acute exacerbation period vs.1.21 $\pm 0.59 \mathrm{ng} / \mathrm{ml}$ during the stable period, without a difference $(p=0.49)$. There was a statistically significant decrease in the CRP serum levels; yet, although not statistically significant a
Ercan Kurtipek MD ${ }^{1}$, Recep Kesli MD², Taha Tahir Bekçi MD1, Fatma Eroğlu MD ${ }^{1}$, Bengi Akın MD1, Hüseyin Kurku MD³, Yüksel Terzi PhD ${ }^{4}$

1 Konya Training and Research Hospital, Department of Chest Disease Konya.

2 Afyon Kocatepe University, School of Medicine, Department of Medical Microbiology, Afyonkarahisar.

3 Konya Training and Research Hospital, Department of Biochemistry, Konya.

4 Ondokuz Mayıs University Faculty of Art and Science Department of Statistics, Samsun, Turkey

Contact information:

Ercan Kurtipek, MD.

Konya Training and Research Hospital Meram, Konya/TURKEY

Tel: (90) 332 3236709-3110

Fax: (90) 3323236723

" kurtipek14@hotmail.com 
remarkable decrease was seen in the suPAR levels obtained before and after the management of exacerbations $(p=0.001$ and $p=0.06$ respectively).

Conclusion: These results support the idea that suPAR, a novel biomarker, might be an important indicator if verified with further prospective studies in evaluating COPD exacerbations and treatment response like CRP used for decades.

\section{Keywords}

suPAR, C-reactive protein, Chronic Obstructive Pulmonary Disease

\section{Introduction}

Chronic obstructivepulmonary disease (COPD) is a disease characterized by a progressive airflow limitation and recurrent acute exacerbations associated with an inflammatory response in lungs to the chronic inhalation of noxious particles and gases [1].

Exacerbations observed during the course of the disease are a major cause of morbidity and mortality. They have an impact on quality of life in patients with COPD, leading to hospitalizations to a considerable extent [2].

A review of COPD epidemiology indicates that according to the World Health Organization (WHO) dataabout 600 million people suffer from COPD all over the world, with 2.3 million people dying each year because of COPD [3]. Furthermore, COPD is currently the fourth leading cause of death among all others, and it is projected to be the third by 2020 [4] Genetic and environmental factors, inflammation and oxidative stress contribute to development of COPD. Some inflammatory mediators such as monocyte-macrophages, CD8 T-lymphocytes, neutrophils, eosinophils and interleukin (IL)-8, leukotriene B4 (LTB4), tumor necrosisfactor (TNF)- $\alpha$ are involved in COPD inflammation.
The main source of pathological findings in COPD is the destructive and structural changes caused by inflammatory products. Any acute exacerbation of COPD leads to increased airway inflammation, and thus increased release of inflammatory mediators $[5,6]$.

C-reactive protein (CRP), the first acute phase reactant discovered, is detected in serum as early as four hours after the damage.

Early and quick diagnosis of COPD exacerbationis very important, particularly in prevention of mortality. Therefore, CRP and procalcitonin are mainly used as biomarkers to determine COPD exacerbation and response. Recently, a new biomarker called suPAR (Soluble form of the urokinase-type plasminogen activator receptor) with significantly elevated levels in diseases such as sepsis and bacteremia has been identified [7-9].

Soluble urokinase-type plasminogen activator receptor (sUPAR) is released from the membranebound plasminogen activator, and is positively correlated with the activation of immune system. Numerous studies on various infections, inflammatory diseases and cancer have shown increased systemic levels of suPAR [10-14]. However, the new biological marker, suPAR has not been studied in demonstrating COPD exacerbation. 
The aim of present study was to determine if sUPAR, as a new biological marker, is as sensitive as CRP in the evaluation of COPD exacerbations and response.

\section{Material Methods}

The COPD patients who presented to the Chest Diseases Clinic between October 2012 and April 2013 were divided into 3 groups; those with stable COPD [SCOPD] $(n=54)$, pre-treatment acute exacerbation COPD [AECOPD] $(n=53)$, and posttreatment AECOPD $(n=52)$. AECOPD and posttreatment AECOPD group consisted of the same patients; Yet, we had an exodus and thus one patient less. Presence of one or more symptoms such as increased amount of sputum, purulence, shortness of breath, chest tightness, and wheezing was considered an acute exacerbation [15, 16]. For SCOPD, patients were required not to have any acute exacerbation symptoms at least in a fourweek period. We excluded those who were younger than 40 years, and pregnant, had a non-COPD disease such as asthma-bronchiectasis-tuberculosis, malignancy (pulmonary and non-pulmonary), chronic renal failure associated with increased serum level of CRP, chronic liver failure, collagen tissue disease, and cardiac diseases including vasculitis. All patients provided a detailed medical history including their smoking status and duration of disease; and their physical examination findings, chest X-rays and grades of dyspnea (according to the ATS dyspnea score) were evaluated;and respiratory function tests, and arterial blood gas parameters were assessed.

Measurement of serum CRP level;Peripheral venous blood samples were obtained using EDTAcontaining blood collection tubes. Then, the samples were centrifuged at $3000 \mathrm{rpm}$ for $5 \mathrm{~min}$ to separate the plasma. The plasma was stored at $-80^{\circ} \mathrm{C}$ in a deep freezer before performing the CRP assays. CRP (Cardio Phase CRP, Siemens Healthcare
Daignostics Products GmbH, Hamburg, Germany) assays were performed by using a fully-automated nephelometric assay system (BN II Seimens Healthcare Diagnostics Inc. Tarrytown, NY, USA). The reference range for CRP was $0.00-5.00 \mathrm{mg} / \mathrm{L}$ in healthy individuals depending on the assay method used.

The plasma samples of patients were stored at $80^{\circ} \mathrm{C}$ in a deep freezer for measurement of suPAR levels like CRP. For suPAR assays, a micro ELISA reactive (Receptor (PLAUR/UPAR) ELISA Kit, Hangzhou Eastbiopharm Co. Ltd. Hangzhou, PRC) and a micro plate reader (Biotek ELx 800, BioTek Instrumentations, Inc, Winooski, VT, USA) were used.

The study protocol was approved by the local ethics committee. A written informed consent was obtained from all subjects.

\section{Statistical Analyses}

All statistical analyses were performed using SPSS statistical package (version 15 for Windows, SPSS; Chicago, III., USA). Descriptive analyses were performed for all variables. The association between two quantitative variables was evaluated with Pearson's correlation coefficient. The results were expressed as means and standard deviations for quantitative variables, and as frequencies for categorical findings. To compare means of two independent groups, student's t test was used, while nonparametric data were analyzed with the MannWhitney $U$ test. The Kruskal-Wallis test was used to compare nonparametric data of several groups. To identify the differences between the aforementioned markers, we performed an unadjusted and adjusted regression analysis and a logistic regression analysis. The level of statistical significance was taken as $p<0.05$.

\section{Results}

The patients with COPD were divided into 3 groups for evaluations: The mean age of groups were SCOPD (62.12 \pm 9.26 years), pre-treatment AECOPD 
Table 1. Demographic characteristics of groups.

\begin{tabular}{l|l|l|l|} 
& \multicolumn{1}{|c|}{$\begin{array}{c}\text { COPD } \\
(\mathbf{n}=54)\end{array}$} & $\begin{array}{c}\text { AECOPD } \\
(\mathbf{n}=53)\end{array}$ & $\begin{array}{c}\text { After } \\
\text { Treatment } \\
\text { COPD } \\
(\mathbf{n}=52)\end{array}$ \\
\hline Age & $62,12+9,26$ & $66.13+10,34$ & $66,30+10,34$ \\
\hline Fev1 & $43,24+14,29$ & $36,07+15,00$ & $42,11+17,62$ \\
\hline pO2 & $64,70+17,03$ & $55,18+12,06$ & $62,64+17,63$ \\
\hline $\begin{array}{l}\text { Smoking } \\
\text { (pack/years) }\end{array}$ & $44,51+34.57$ & $39.50+33.54$ & $38.92+32.46$ \\
\hline $\begin{array}{l}\text { mMRC } \\
\text { (dispnea score) }\end{array}$ & $2.56+1.00$ & $4.00+1.00$ & $3.21+1.17$ \\
\hline $\begin{array}{l}\text { SCOPD: } \text { Stable chronic obstructive pulmonary disease. } \\
\text { AECOPD: Acute exacerbation chronic obstructive }\end{array}$ \\
$\begin{array}{l}\text { Fev1: Force expiratory volume second 1 } \\
\text { mMRC: } \text { Modified medical research council }\end{array}$ \\
\hline
\end{tabular}

Table 2. CRP and sUPAR results between SCOPD and AECOPD.

\begin{tabular}{|l|c|c|c|}
\hline & $\begin{array}{c}\text { SCOPD } \\
(\mathbf{n}=54)\end{array}$ & $\begin{array}{c}\text { AECOPD } \\
(\mathbf{n}=53)\end{array}$ & P value \\
\hline CRP $\mathrm{mg} / \mathrm{L}$ & $5,02 \pm 6,31$ & $54,82 \pm 56,63$ & 0.0001 \\
\hline suPAR $\mathrm{ng} / \mathrm{ml}$ & $1,21 \pm 0,59$ & $1,28 \pm 0,52$ & 0.49 \\
\hline & & $\mathbf{p}<\mathbf{0 . 0 5}$ statistically significant \\
\hline
\end{tabular}

Table 3. CRP and suPAR results between AECOPD and After Treatment COPD.

\begin{tabular}{|c|c|c|c|}
\hline & $\begin{array}{c}\text { AECOPD } \\
(n=53)\end{array}$ & $\begin{array}{c}\text { After } \\
\text { Treatment } \\
\text { COPD }(n=52)\end{array}$ & $P$ value \\
\hline CRP mg/L & $54,82 \pm 56,63$ & $5,93 \pm 5,20$ & 0.001 \\
\hline suPAR ng/ml & $1,28 \pm 0,52$ & $1,020 \pm 0,41$ & 0.06 \\
\hline
\end{tabular}

(66.13 \pm 10.34 years), and post-treatment AECOPD (66.30 \pm 10.34 years). The demographic characteristics of groups are shown in Table 1.

All patients were male. CRP and suPAR were measured in all groups.

The sUPAR levels for SCOPD was $1.21 \pm 0.59$, for AECOPD was 1.28 \pm 0.52 , and post-treatment AECOPD 1.02 \pm 0.41 (Table 2-3). Accordingly, in the AECOPD group the sUPAR level was elevated during exacerbations compared to SCOPD; yet without a statistical significance $(p=0,49)$. In addition, post-treatment suPAR levels were lower than pre-treatment in the AECOPD group. However the difference was not statistically significant $(p=0,06)$.

CRP levels of SCOPD group was $5.02 \pm 6.31$, of pre-treatment AECOPD 54.82 \pm 56.63 , and posttreatment AECOPD 5.93 \pm 5.20 . The CRP levels of pre-treatment AECOPD levels were higher than both groups and statistically significant $(p<0,05)$ (Table 2-3).

The area under curve (AUC) value for CRP was 0.88, $(p=0.001)$ and cut off value was 7,67. Additionally, sensitivity was $84.9 \%$ and specifity was $85.0 \%$. On the other hand, the AUC value for suPAR was $0.621(p=0.01)$ (Figure 1).

According to Spearman's correlation analysis, the correlation between CRP and suPAR was $r=0.147$ $(p=0.06)$. Therefore, it was concluded that suPAR was not as sensitive as CRP as a biomarker of exacerbations in patients with COPD (Figure 2). 
Figure 1. Results for ROC analysis of CRP and suPAR levels in COPD patients as markers of exacerbations (0.888 and 0.621, respectively).

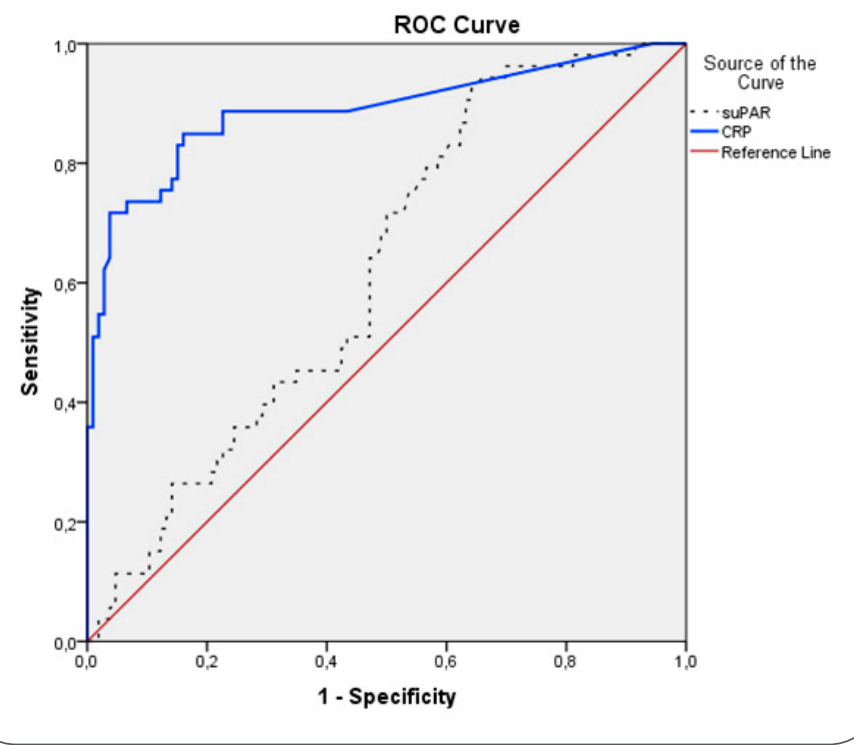

Figure 2. Association between levels of CRP and suPAR $(p=0.06)$.

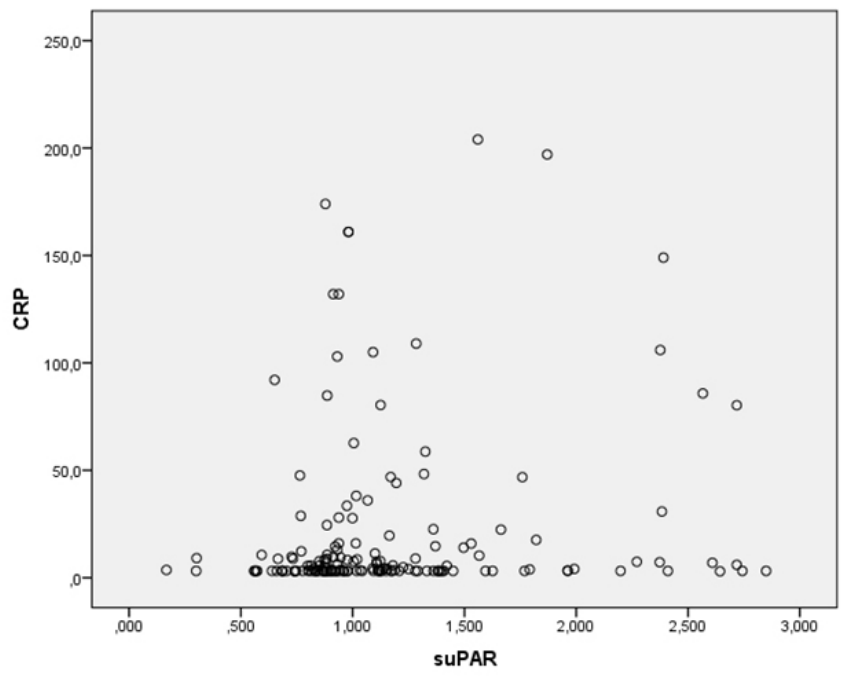

\section{Discussion}

In the present study, plasma suPAR levels of AECOPD patients were higher than the SCOPD group; yet this difference is not statistically signifcant. Likewise pre-treatment plasma suPAR levels of AECOPD patients was higher than post-treatment AECOPD; yet without statistically significant. Backes et al. showed that diagnostic value of suPAR is low in demonstrating inflammation, which is also consistent with our findings [17]. Regarding the SUPAR levels of SCOPD patients throghout an inflammation there is, acording to our best knowledge, only one report in the current literature [18]. In that study, the plasma suPAR levels of the SCOPD patients were signicantly higher than that of the healthy controls indicating the these findings might reflect the inlammatory process in SCOPD.

Additionally, Gustafsson et al. compared the suPAR levels in patients with severe sepsis with other inflammatory markers, and showed that suPAR can be used in predicting severity and mortality of sepsis [19]. Similarly, Donadello et al.indicated that suPAR can be used as prognostic biomaker in sepsis [20]. More than 150 biological markers have been studied in patients with sepsis, however most of them are not routinely used in daily practice [21].

In the present study, CRP levels of both SCOPD and post-treatment AECOPD were lower compared to pre-treatment AECOPD in line with the reduced inflammation. This difference in the CRP levels of both groups were statistically significant.

In line with the present study, Hurst et al. showed that CRP is the most practical and best known biomarker in detecting COPD exacerbations [22].

This is the first pilot study on suPAR concentrations in patients with SCOPD and AECOPD.

Limitations of the study: The limitations of our study is the lack of a comparison with healthy controls, limited patient series, and that all participants were male. 
In conclusion, we believe that the new biomarker, suPAR is not as sensitive as CRP in demonstrating COPD exacerbations, and its use as a marker of exacerbation may be limited in patients with COPD. Future studies with larger patient series and with a control group consisting of healthy patients may reflect the inflammatory process in AECOPD patients based on plasma suPAR levels. Yet, before it can be used like CRP further clinical studies including more patients to evaluate suPAR in patients with COPD are needed.

\section{References}

1. Pauwels RA. National and interntional guidelines for COPD. The need for evidence. Chest 2000; 117: 20-2.

2. Li J, Zhao HJ, Wang FY, Dong HM, Cai SX. Risc factors for inhospital mortality in patients with acute exacerbation of chronic obstructive pulmonary disease. ZhonghuaYi XueZa Zhi. 2013: 14; 93(18): 1374-7.

3. Busset AS. Risk factors for COPD. Eur Respir Rev 1996; 6: 253-8.

4. Murray CJL, Lopez AD. Alternative projections of morta- lity and disability by cause 1990-2020: Global burden of disease study. Lancet 1997; 349: 1498-504.

5. Chung KF. Cytokines in chronic obstructive pulmonary disease. Eur Respir J 2001; 18 (Suppl 34): 50-9.

6. Okamura JM, Miyagi JM, Tenada K, Hokoma Siafakas NM, Bouros D. Management of acute exacer- bation of chronic obstructive pulmonary disease. Eur Respir Mon 1998; 3: 264277.

7. Huttunen R, Syrjanen J, Vuento R, Hurme M, Huhtala $H$, Laine J, Pessi T, Aittoniemi J: Plasma level of soluble urokinase-type plasminogen activator receptor as a predictor of disease severity and case fatality in patients with bacteraemia: a prospective cohort study. J Intern Med 2011, 270: 32-40.

8. Mölkänen $T$, Ruotsalainen $E$, Thorball $C W$, Järvinen A.Elevated soluble urokinase plasminogen activator receptor (suPAR) predicts mortality in Staphylococcus aureus bacteremiaEur J Clin Microbiol Infect Dis. 2011 Nov;30(11):1417-24. doi: 10.1007/ s10096-011-1236-8. Epub 2011 Apr 12.

9. Eugen-Olsen J. suPAR- a future risc marker in bacteremia. J Intern Med 2011; 270(1): 29-31.

10. Wrotek A, Pavlik K, Jackowska T.Soluble receptor for urokinase plasminogen activator in community-acquıred pneumonia in children. Adv Exp Med Biol 2013: 788; 329-334.

11. Loonen AJ, de Jager CP, Tosserams J, Kusters R et all. Biomarkers and molecular analysis to improve bloodstream infection diagnostics in an emergency care unit[-NCBIPlus One 2014 June 27;9:1e:87315.doi: 10.1371/journal.pone.0087315.eCollection 2014.

12. Fidan E, Menteşe A, Deger Ö et all. Diagnostic and prognostic significance of CA IX and suPAR in gastric cancer. Med. Oncol. 2013: 30(2): 540-549. doi:10.1007/s12032-013-540-9. Epub 2013 Mar 20

13. Edsfeldt A, Nitulescu M, Grufman H. Soluble urokinase plasminogen activator receptor is associated with inflammation in the vulnarable human atherosclerotic plaque. Stroke 2012 Dec 43(12): 3305-3312. 
14. Suberviola B,Castellanos Ortega A, Ruiz Ruiz A et all. Hospital mortality prognostication in sepsis using the new biomarkers sUPAR and proADM in a single determination on ICU admission. Intensive Care Med 2013; 39(11): 1945-52.

15. Siafakas NM, Bouros D. Management of acute exacerbation of chronic obstructive pulmonary disease. Eur Respir Mon 1998;3:264-77

16. Anthonisen N. Epidemiology and the lung health study. Eur Respir Rev 1997;7:202-205.17. Backes Y, van Der Sluijs KF, Mackie DP et al. Usefulness of suPAR as a biological marker in patients with systemic inflammation or infection: a systematic review. Intensive Care Med (2012) 38: 1418-1428.

18. Can Ü, Güzelant A, Yerlikaya FH, Yosunkaya ş. The role of serum soluble urokinase-type plasminogen activator receptor in stable chronic obstructive pulmonary disease. J Investig Med. 2014 Oct; 62(7): 938-43.

19. Gustafsson A, Ljunggren L, Bodelsson M, Berkestedt I. The prognostic value of suPAR Compared to Other Inflammatory Markers in Patients with Severe Sepsis. Biomarker Insights 2012 : 7; 39-44.

20. Donadello K, Scoletto S, Covajes C, Vincent JL. suPAR as a prognostic biyomarker in sepsis. BMC Medicine 2012; 10: 2-10.

21. Pierrakos C, Vincent JL.2010 Sepsis biomarkers: a review. Crit Care 14:R15 doi: 10.1186/cc8872. Epub 2010 Feb 9.

22. Hurst JR, Donaldson GC, Perera WR et al.Use of plasma biomarkers at exacerbation of chronic obstructive pulmonary disease. Am J Respir Crit Care Med. (2006)15; 174(8): 867-874.

\section{Comment on this article:}

\section{f) $[$ in $8+\mathbf{S} P$}

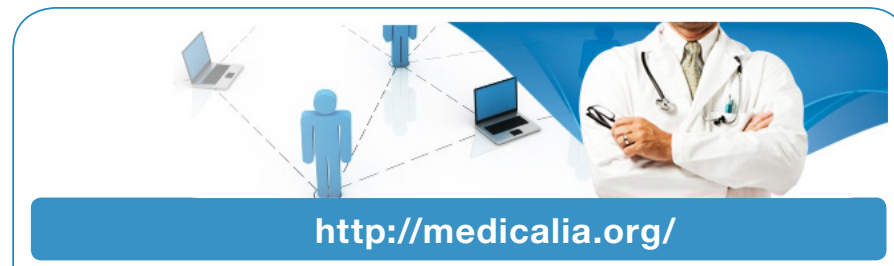

Where Doctors exchange clinical experiences, review their cases and share clinical knowledge. You can also access lots of medical publications for free. Join Now!

\section{Publish with iMedPub}

\section{http://www.imed.pub}

International Archives of Medicine is an open access journal publishing articles encompassing all aspects of medical science and clinical practice. IAM is considered a megajournal with independent sections on all areas of medicine. IAM is a really international journal with authors and board members from all around the world. The journal is widely indexed and classified Q1 in category Medicine. 